\title{
Diabetes-related complications and practices of foot inspections: NHANES 2009-2010
}

\author{
Judith Aponte \\ Correspondence: jap@hunter.cuny.edu \\ Hunter-Bellevue School of Nursing, Hunter College and Graduate Center, City University of New York, New York.
}

\begin{abstract}
Objective: The National Health and Nutritional Examination Survey (NHANES) 2009-2010 was utilized to examine risk factor variables of diabetes-related complications and foot inspection practices of health care providers (HCPs) and of people with diabetes among five ethnic groups.

Design: The study design conducted was descriptive using the NHANES 2009-2010 secondary dataset. The sample included individuals 40 years of age and older who self-reported a diabetes diagnosis.

Measurements: The risk factor variables (glycated hemoglobin (A1c), cigarette smoking cigarettes, systolic blood pressure (SBP) and diastolic blood pressure (DBP), triglyceride, low-density lipoprotein (LDL) high-density lipoprotein (HDL), albumin and creatinine levels, and dilated pupil exams) for three diabetes-related complications (cardiovascular disease (CVD), nephropathy, retinopathy), and practices of HCPs and people with diabetes for checking the feet for ulcers were measured..

Results: Chi-squares were compared among five ethnic groups and particular variables showed significant differences in between specific groups using SAS 9.2 @. The groups with the highest prevalence of risk factors for diabetes-related complications are Non-Hispanic Black followed by Mexican American. This study demonstrates disparities among different ethnic groups with diabetes and the need for continued efforts to increase awareness of the importance of diabetes follow-up care, and of maintaining controlled A1c, blood pressure, lipid, creatinine and albumin levels.

Conclusion: The findings of this study will add to the diabetes literature highlighting current data on A1c, SBP and DBP ranges, triglyceride, LDL, HDL, albumin, and creatinine levels dilated pupil exam, and foot inspection practices of HCPs and people with diabetes.
\end{abstract}

keywords: diabetes, secondary analysis, NHANES, foot inspections.

\section{Introduction}

Diabetes is a disease that is growing in epidemic proportions. In 2007, there were a total of 1.6 million new cases of adults diagnosed with diabetes [1], and by 2010, the number of new cases rose to 1.9 million [2]. When comparing diabetes among adults of different race/ethnicity, in 2007, the group with the highest rate was for Non-Hispanic Blacks (NHB) (11.8\%), followed by Hispanics (10.4\%), Asian Americans (7.5\%), and Non-Hispanic Whites (NHW) (6.6\%), by 2010 the diabetes rates had increased for all race/ethnicities (NHB (12.6\%), Hispanics (11.8\%), Asian Americans (8.4\%), and NHW (7.1\%).

According to the ADA [3] Diagnosis and Classification of Diabetes Mellitus, diabetes is defined as a disease characterized by hyperglycemia, in which the body does not produce or properly use insulin or both. This inadequate production or use of insulin interferes with healthy metabolism of carbohydrates, proteins, fats, ultimately resulting in abnormalities in the structure and function of blood vessels and nerves. Diabetes is a chronic disease that affects many organ systems throughout the body which can lead to diabetes-related complications [4]. Diabetes-related complications develop as a result of injury and damage to the small blood vessels of the body, resulting in microvascular complications and damage to the large blood vessels, resulting in macrovascular complications [5]. Examples of microvascular complications include diabetic nephropathy, and retinopathy, including foot ulcers and amputations. Among macrovascular complications cardiovascular disease (CVD) is the most common complication in people with diabetes [6]. Microvascular and macrovascular complications are a major cause of morbidity and mortality in people with diabetes [7].

\section{Diabetes-related Complications}

As the ADA [8] recommends, people with diabetes who have stable glycemic control should have glycated hemoglobin (A1c) testing performed at least 2-times a year and for those whose therapy has changed or who have unstable glycemic control should have testing performed every 3-months. They also recommend that people with diabetes: quit smoking; 
have their blood pressure measured during every routine diabetes visit; have annual testing of triglyceride, low-density lipoprotein (LDL), high-density lipoprotein (HDL), albumin and creatinine levels, and an annual dilated pupil exam; and conduct daily self foot inspections. In addition the NIDDK [9] recommends that health care providers (HCPs) caring for people with diabetes check their feet at every diabetes visit. A1c. According to the NIDDK [10] and ADA [3] the A1c test is a blood test that reflects a person's average of blood glucose level over a 2 to 3 month period of time. Glycemic control plays a critical role in the management of diabetes, particularly due to the direct impact it has in the development of microvascular and macrovascular complications when levels are high. Reductions in hyperglycemia (i.e., high glucose levels) and management of diabetes-related risk factors (e.g., blood pressure) significantly reduce microvascular and macrovascular complications in people with diabetes [3]. Studies such as the UKPDS reported a $30-35 \%$ reduction in microvascular complications and a $14 \%$ to $16 \%$ decrease in macrovascular complication for every $1 \%$ reduction of A1c percentage [11]. A1C testing is an important measure and guide for managing diabetes.

CVD. The American Heart Association (AHA) [12] defines CVD as a "heart and blood vessel disease". Diabetes is associated with a high risk of CVD [13], and is an independent risk factor for CVD [14]. People with diabetes have a 4-fold greater risk for having a CVD event than in those without diabetes [14]. CVD is the primary diagnosis for diabetes-related hospital admissions [15], and accounts for $70 \%$ of all deaths in people with diabetes [6].

Nephropathy. According to the National Institute of Diabetes and Digestive and Kidney Diseases (NIDDK) [16] diabetic nephropathy is a kidney disease that affects kidney function. It affects the blood vessels in the kidneys which act as filters to remove waste products and extra water from the blood [17]. The most common cause of kidney disease is diabetes, which accounts for approximately $44 \%$ of the new cases of kidney disease. Progression of kidney disease leads to kidney failure and if left untreated leads to end-stage renal failure (ESRD), resulting in either dialysis or kidney transplant [18]. Diabetes accounts for approximately 180,000 people with kidney failure [19], and is the most common cause of ESRD in the U.S. [20]. In 2007, kidney disease accounted for $57.4 \%$ of all deaths in people with diabetes [15].

Retinopathy. The American Optometric Association [21] defines diabetic retinopathy as a condition which causes progressive damage to the blood vessels of the retina. Such damage includes, microaneurysms, blockage and/or leakage of blood vessels, resulting in vision loss. According to the ADA [2], from 2005 to 2008 , there were 4.2 million (28.5\%) people with diabetes aged 40 years or older who had diabetic retinopathy. Retinopathy is the most common microvascular complication of diabetes and the leading cause of blindness in people with diabetes.
Ulcers and amputations. Diabetes causes damage to small blood vessels of the legs and feet, which inhibit the sensation of pain and prevents adequate oxygenation of tissue. This damage can cause the development of chronic wounds or ulcers to the lower extremity (LE) making foot inspections an important aspect of diabetes care and management. Between 2000 and 2002 , approximately $12 \%$ of people with diabetes have had a foot ulcer [22]. If foot wounds or ulcers are left untreated, this puts a person at risk for a nontraumatic lower extremity amputation (LEA) [23]. Hence, people with diabetes have more than a $60 \%$ chance of having a nontraumatic LEA [2] and have a 15 to 40 times greater risk of nontraumatic LEA than in those without diabetes [24]. Foot ulcers and amputations are an important cause of morbidity and mortality in patients with diabetes [25], making foot inspections by both the HCP at every visit and daily self feet inspections in people with diabetes essential.

Overall, diabetes is the leading cause of new cases of renal failure, blindness, and non-traumatic LEA in the U.S. [26]; and CVD is the leading cause of death in people with diabetes [27].

In order to prevent and manage these life-threatening diseases, it is essential and critical to examine the prevalence of risk-factors of diabetes-related complications and foot inspection practices of HCPs and people with diabetes. The ADA annually revises the Standards of Medical Care for clinicians, which provides diabetes care screening, diagnostic and treatment guidelines. Included in the Standards of Medical Care, are recommended measures that need to be performed and monitored for the prevention and management of diabetes-related complications. For this article, particular risk factor measures for diabetes-related complications (i.e., CVD, nephropathy, and retinopathy) and foot inspection practices of HCPs and people with diabetesreported in the ADA Standards of Medical Care [8].

\section{Purpose}

The purpose of this study was to investigate risk factors for diabetes-related complications and foot inspection practices of HCPs and people with diabetes in five ethnic groups (Mexican American, NHB, NHW, Other Hispanic and Other race) of the U.S. population, 40 years of age and older with diabetes, during the years 2009 through 2010, using the raw data of the National Health and Nutrition Examination Survey (NHANES) 2009-2010 data set. Although this survey entails 2 years worth of raw data these study findings provide vital information on the most current risk-factor data of three diabetes-related complications and foot inspection practices of HCPs and those with diabetes in five different ethnic groups with diabetes and data on differences among the groups.

\section{Methods \\ Design}

The NHANES 2009-2010 survey was used to investigate rates and differences of risk-factors of diabetes-related complications 
Judith Aponte. Journal of Diabetes Research and Clinical Metabolism 2012,

and foot inspection practices of HCPs and those with diabetes in individuals (i.e., Mexican American, Other Hispanic, NHW, $\mathrm{NHB}$, and Other/Multi-racial) 40 years and older of age and diagnosed with diabetes. The NHANES 2009-2010 survey is the most current data set available for public use. Aponte [28] describes in detail the method National Center for Health Statistics (NCHS) uses to collect the NHANES data.

\section{Sample}

The current study utilizes data on the variables cigarette smoking, yearly dilated pupils, yearly HCPs feet inspections, daily self feet inspections by people with diabetes, which were collected from interview data, as well as A1c, SBP and DBP ranges, and triglyceride, $\mathrm{LDL}, \mathrm{HDL}$, albumin, and creatinine levels, collected from laboratory findings in NHANES.

Given that the NHANES 2009-2010 survey did not collect data on aspirin therapy, frequency of comprehensive eye examinations, distal symmetric polyneuropathy (DPN) examinations or frequency of comprehensive foot exams (i.e., inspection, assessment of foot pulses, and testing for sensation) these variables were not examined in this current study. Since DPN examinations were not conducted the diabetes complication of neuropathy could not be examined. For early identification of foot ulcers and amputations, since frequency of comprehensive foot exams was not collected, the variable of "frequency doctor checks feet for sores or irritations" was used in this current study. Secondary analysis of the raw data utilized the sample weight representing the sample population provided in the NHANES 2009-2010 Public Data General Release File Documentation [29].

\section{Sample Selection Procedures}

In NHANES 2009-2010, data on risk factors of diabetes-related complications and on foot inspection practices of HCPs and those with diabetes were collected on those 40 years and older and with diabetes. A diagnosis of diabetes was based on self-report, indicated in a diabetes questionnaire data file which included the question: "diagnosis of diabetes by a doctor or health care professional." In 2011 the ADA [3] included A1c testing as a measurement for diagnosing diabetes (i.e., $A 1 c \geq 6.5 \%$ ). Given that this study sample is of those with diabetes and since people with diabetes may have an A1c $\geq 6.5 \%$, indicating both elevated glycemic levels and a need for a change in the treatment regimen (e.g., medications), A1c in this study was used as a screening and management measure and not a diagnostic measure. For the current study, sample subjects were limited to members of all ethnic groups, ages 40 years and older, who had diabetes.

Secondary analysis of NHANES 2009-2010 raw data was approved with exempt status by the IRB of "Hunter College, City University of New York (CUNY)".

\section{Data Collection}

The data collection methods used for the NHANES 2009-
2010 raw data consisted of two phases. Phase 1 consisted of two questionnaires. One questionnaire was the Family Questionnaire (FQ), administered to all sample persons 16 years and older; and a second questionnaire was the Sample Person Questionnaire (SPQ), administered to all sample persons, with questions about health and nutritional status, including self-report of diabetes diagnosis.

Phase 2 was conducted in a mobile examination center (MEC). Each participant was given a physical exam with a laboratory component with a blood test of A1c. Two additional questionnaires were administered at this time, covering sensitive areas (e.g., reproductive health and illegal drug use) in NHANES 2009-2010 Phase 2.

Given the sensitive nature of Phase 2 questions in NHANES 2009-2010, they were not administered face-to-face but instead were administered on a computer in a private room in the MEC, using audio computer-assisted self-interview (ACASI) and computer-assisted personal interview (CAPI). Each health-related topic contained questions administered to specific age groups. ACASI questions included topics of alcohol use (age 12-19), food security (age 12-15), drug use (age 12-69), sexual behavior (age 14-69) and tobacco use (age 12-19). CAPI questions included topics of alcohol use (age 20 and older), bowel health (age 20 and older), current health status (age 12 and older), depression (age 12 and older), dietary (age 12-69), kidney (age 20 and older), pesticide use ( age 8 and older), physical activity (age 12-15), reproductive health (females age 12 and older), tobacco (age 20 and older), and volatile toxicants use (age 12 and older), weight history (age 8-15). The interviewer provided a brief training session to the participant and then left the room before the participant began to answer any of the Phase 2 questions, thereby providing maximum privacy. The questions were either in English or Spanish, based on participant preference. Participants could hear the questions through earphones and read them on the computer screen, alleviating any potential embarrassment for those who had low literacy. Questions were answered by touching the screen, allowing participants to move at their own speed, and participants could refuse to answer any question.

The NHANES 2009-2010 [30] codebooks of these questionnaires provided quality assurance procedures that include built-in checks and edits that limit the introduction of errors NCHS. NHANES 2009-2010 data are stored by NCHS and can be downloaded for review and analysis.

Current Study Collection Test and Measures. For the current study, raw data from NHANES 2009-2010 were used to measure risk factors of three diabetes-related diabetes complications (i.e., CVD, nephropathy, retinopathy), and foot inspection practices of HCPs and of people with diabetes (see Table 2).

For descriptive analysis, each variable was examined independently. Numerical values differentiating normal, elevated and high levels were created for A1c, SBP, DBP ranges, triglyceride, LDL, HDL, albumin, and creatinine levels, and 
categorical values were created for cigarette smoking, dilated pupils, foot inspection practices of HCPs and of people with diabetes.

\section{Data Analysis}

In this secondary analysis, NHANES 2009-2010 raw data for all individuals (i.e., Mexican American, Other Hispanic, NHW, $\mathrm{NHB}$, and Other/Multi-racial) 40 years and older of age and diagnosed with diabetes were analyzed using $\mathrm{SAS}^{\odot}$ version 9.2. The recommended weights of the NCHS, available in the NHANES 2009-2010 data set [31] were used for all data analyses. $\mathrm{NCHS}$ [32] provided a mechanism whereby future researchers could weight the original raw data and meaningfully analyze it. Sample weights for each data set were used representing the sample population provided by NHANES 2009-2010. The findings which are reported are those that were or were not significant when using $\mathrm{SAS}^{\circledR}$ version 9.2.

Descriptive statistics were computed for the risk-factor variables (A1c, cigarette smoking, SBP, DBP, triglyceride, $\mathrm{LDL}$, and $\mathrm{HDL}$, albumin, and creatinine levels and dilated pupil exam) of three diabetes-related complications (i.e., CVD, nephropathy, retinopathy), and of feet inspection practices (i.e., frequency of yearly HCPs feet inspections, and of daily foot self-inspection practices of people with diabetes selffeet inspections), and A1c in all five ethnic groups (Mexican American, NHB, NHW, Other Hispanic and Other/Multi-racial) 40 years and older with diabetes. Chi-squares were computed to compare differences in the variables between ethnic groups (see Table 3).

\section{Results}

Of the total weighted sample $(\mathrm{N}=17,343,454)$ comprised all participants 40 years and older, who reported a diagnosis of diabetes from a doctor or health care professional. Of those, the largest ethnic group with diabetes was NHW (59\%), followed by NHB (18\%), equal for Mexican American and Other/Multi-racial (9\%) and Other Hispanic (5\%) (see Table 1).

For each of the 5 ethnic groups, the prevalence of the three diabetes-related complication variables (CVD, nephropathy, and retinopathy) and of foot inspection practices of HCPs and people with diabetes in checking the feet, were analyzed for percentage sum, weighted total, and statistical significance (see Table 2).

Of all ethnicities combined, $55 \%(n=9,633,695)$ had a controlled A1c. Four of the five ethnic groups (NHBs $(62 \%)$, Other Hispanics (60\%), Other/Multi-racials (59\%), NHWs (55\%), and Mexican Americans (39\%) had over $50 \%$ of the sample with a controlled A1c ( $<7 \%)$. Mexican Americans (61\%) were the largest group who had an elevated (7-9\%) or high ( $>9 \%)$ A1c. Although A1c in Mexican Americans was significantly higher than Other Hispanics(-0.19\%), NHW (-0.27\%) and NHB (-0.26\%).

Although under CVD, most people for each ethnic group never smoked (between $24 \%$ and $41 \%$ ), the majority refused (between $42 \%$ and $61 \%$ ) to answer that question which does not provide a clear understanding of the number of people who are either smokers or non-smokers. Hence, the lack of data does not provide a clear understanding of the number of sample members at risk of CVD as a result of smoking. Smoking was not significantly different for any of the five ethnic groups.

The largest number of sample members with an elevated $(\geq 130-139 \mathrm{mmHg})$ and high $(\geq 140 \mathrm{mmHg})$ SBP was among NHBs (52\%), while the percentage was equal for Mexican Americans, Other Hispanics, NHWs (47\%), and Other/Multiracials (42\%). For DBP, the largest group with elevated $(\geq 80$ $\leq 89 \mathrm{mmHg}$ ) and high $(\geq 90 \mathrm{mmHg})$ DBP ranges was among Other Hispanics (27\%), NHBs (24\%), Mexican Americans (20\%), Other/Multi-racials (15\%), and NHWs (14\%). For all ethnic groups, $47 \%$ had elevated $(\geq 130-139 \mathrm{mmHg})$ and high $(\geq 140$ $\mathrm{mmHg})$ SBP and $17 \%$ had elevated $(\geq 80-\leq 89 \mathrm{mmHg})$ and high ( $>90 \mathrm{mmHg}$ ) DBP. Overall, the two largest groups with a combined elevated and high SBP and DBP were among NHBs (76\%) and Other Hispanics (74\%). Although SBP was not significantly different for any of the five groups, DBP in NHWs was significantly higher than NHB $(0.12 \mathrm{mmHg})$.

Although most people in this sample with diabetes had normal triglyceride levels ( $<150 \mathrm{mg} / \mathrm{dl})(82 \%)$, the largest group with elevated triglyceride levels $(\geq 150 \mathrm{mg} / \mathrm{dl}$ ) were Other Hispanics (38\%), NHWs (20\%), Mexican Americans (19\%), Other/Multi-racials (16\%), and NHBs (6\%). There were $70 \%$ of all ethnic groups who had elevated HDL levels $(<50 \mathrm{mg} / \mathrm{dl})$, while $80 \%$ had normal LDL $(<100 \mathrm{mg} / \mathrm{dl})$ levels. The largest groups with elevated HDL levels were among NHWs (73\%), Other Hispanics (69\%), Other/Multi-racials (67\%), NHBs (65\%), and Mexican Americans (62\%). For LDL, the largest group with elevated levels was among Other Hispanics (36\%), Mexican Americans (25\%), NHBs (22\%), NHWs (18\%), and Other/Multiracials (15\%). Overall, these rates show that over $16 \%$ of all ethnic groups smoke cigarettes, $18 \%$ have elevated triglyceride levels, $70 \%$ have elevated HDL levels and $20 \%$ have elevated LDL levels. For differences among ethnic groups, triglyceride levels were significantly different for Other Hispanics and $\mathrm{NHBs}$ when compared separately from Mexican Americans; for $\mathrm{NHBs}$, NHWs, Other/Multi racials when compared separately

Table 1. Percentage of different ethnic groups 40 years and older with diabetes.

\begin{tabular}{llc}
\hline $\begin{array}{l}\text { Weighted \% } \\
\text { Ethnicity }\end{array}$ & $\mathbf{N}=\mathbf{1 7 , 3 4 3 , 4 5 4}$ & $\mathbf{1 0 0 \%}$ \\
\hline Mexican American & $1,553,153$ & $9 \%$ \\
Other Hispanic & 880,210 & $5 \%$ \\
Non-Hispanic White & $10,259,138$ & $59 \%$ \\
Non-Hispanic Black & $3,041,008$ & $18 \%$ \\
Other/Multi-Racial & $1,609,945$ & $9 \%$ \\
\hline
\end{tabular}


Judith Aponte. Journal of Diabetes Research and Clinical Metabolism 2012,

http://www.hoajonline.com/journals/pdf/2050-0866-1-6.pdf

Table 2: Gender distribution and prevalence of measures for risk factors of diabetes-related complications in people 40 years and older with diabetes Alc: glycated hemoglobin, CVD: cardiovascular disease, HTN: hypertension, SBP: systolic blood pressure, DBP: diastolic blood pressure, HDL: high density lipoprotein, LDL: low density lipoprotein, HCP: health care provider; all the number of subjects are weighted. ${ }^{*}$ Significance at $\mathrm{p}<0.05$

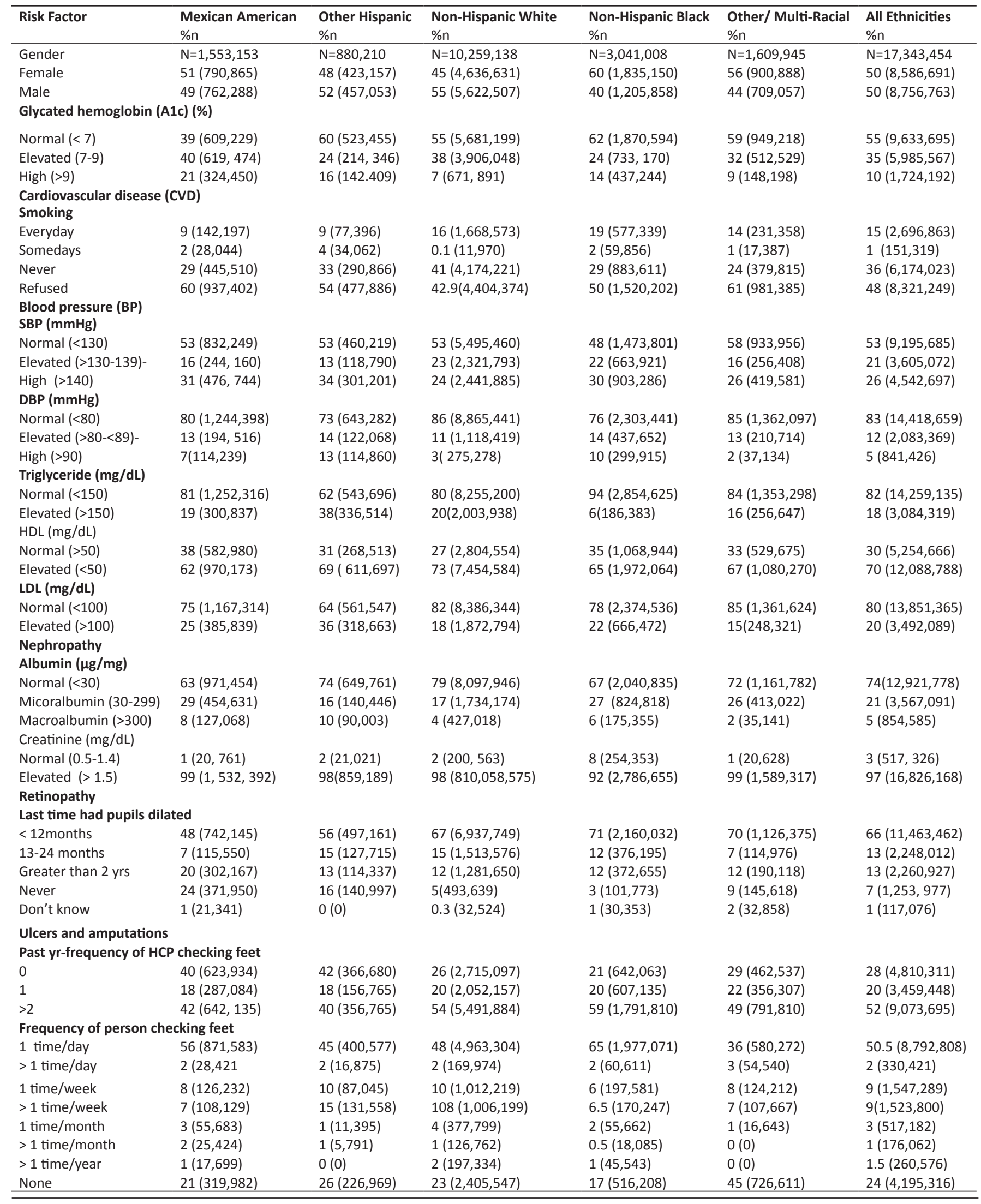


Judith Aponte. Journal of Diabetes Research and Clinical Metabolism 2012, http://www.hoajonline.com/journals/pdf/2050-0866-1-6.pdf

Table 3. Differences in risk factors of diabetes-related complications and foot inspection practices between ethnic groups.

*Significance at $\mathrm{p}<0.05$

\begin{tabular}{|c|c|c|c|c|}
\hline $\begin{array}{l}\text { Risk factor } \\
\text { variable }\end{array}$ & $\begin{array}{l}\text { Referent } \\
\text { group }\end{array}$ & Ethnic group & $\mathbf{x} 2$ & p \\
\hline \multirow[t]{4}{*}{ A1c } & \multirow[t]{4}{*}{$\begin{array}{l}\text { Mexican } \\
\text { American }\end{array}$} & Other Hispanic & -0.19 & $0.04 *$ \\
\hline & & NHW & -0.27 & $0.00 *$ \\
\hline & & NHB & -0.26 & $0.00 *$ \\
\hline & & Other/Multi-racial & -0.19 & 0.1 \\
\hline \multirow[t]{4}{*}{ DBP } & \multirow[t]{4}{*}{ NHW } & $\mathrm{NHB}$ & 0.12 & $0.01 *$ \\
\hline & & Mexican American & 0.63 & 0.25 \\
\hline & & Other Hispanic & 0.11 & 0.08 \\
\hline & & Other/Multi-racial & 0.43 & 0.6 \\
\hline \multirow[t]{9}{*}{ Triglyceride } & \multirow[t]{4}{*}{$\begin{array}{l}\text { Mexican } \\
\text { American }\end{array}$} & Other Hispanic & 0.11 & $0.02 *$ \\
\hline & & NHW & -0.01 & 0.83 \\
\hline & & NHB & -0.13 & $0.00 *$ \\
\hline & & Other/Multi-racial & -0.05 & 0.4 \\
\hline & \multirow[t]{3}{*}{$\begin{array}{l}\text { Other His- } \\
\text { panic }\end{array}$} & $\mathrm{NHB}$ & -0.25 & $<0.0001^{*}$ \\
\hline & & NHW & -0.12 & $0.00 *$ \\
\hline & & Other/Multi-racial & -0.16 & $0.01 *$ \\
\hline & NHW & NHB & -0.12 & $0.00^{*}$ \\
\hline & & Other/Multi-racial & -0.04 & 0.45 \\
\hline \multirow[t]{4}{*}{ LDL } & \multirow[t]{4}{*}{$\begin{array}{l}\text { Other His- } \\
\text { panic }\end{array}$} & Mexican American & -0.07 & 0.18 \\
\hline & & NHW & -0.11 & $0.02 *$ \\
\hline & & NHB & -0.08 & 0.1 \\
\hline & & Other/Multi-racial & -0.13 & 0.08 \\
\hline \multirow[t]{7}{*}{ Albumin } & \multirow[t]{4}{*}{$\begin{array}{l}\text { Mexican } \\
\text { American }\end{array}$} & Other Hispanic & -0.07 & 0.37 \\
\hline & & NHW & -0.18 & $0.00 *$ \\
\hline & & $\mathrm{NHB}$ & -0.05 & 0.41 \\
\hline & & Other/Multi-racial & -0.13 & 0.18 \\
\hline & \multirow[t]{3}{*}{ NHW } & NHB & 0.12 & $0.03 *$ \\
\hline & & Other Hispanic & 0.1 & 0.16 \\
\hline & & Other/multi-racial & 0.04 & 0.64 \\
\hline \multirow[t]{4}{*}{ Creatinine } & \multirow[t]{4}{*}{ NHB } & Mexican American & 0.14 & $0.00 *$ \\
\hline & & Other Hispanic & 0.12 & $0.04^{*}$ \\
\hline & & NHW & 0.12 & $0.00 *$ \\
\hline & & Other/Multi-racial & 0.1 & 0.15 \\
\hline \multirow[t]{7}{*}{ Pupils } & \multirow[t]{4}{*}{$\begin{array}{l}\text { Mexican } \\
\text { American }\end{array}$} & Other Hispanic & -0.14 & 0.2 \\
\hline & & NHW & -0.46 & $<0.0001^{*}$ \\
\hline & & $\mathrm{NHB}$ & -0.5 & $<0.0001^{*}$ \\
\hline & & Other/Multi-racial & -0.4 & $0.00 *$ \\
\hline & \multirow[t]{3}{*}{$\begin{array}{l}\text { Other His- } \\
\text { panic }\end{array}$} & NHW & -0.31 & $0.00^{*}$ \\
\hline & & $\mathrm{NHB}$ & -0.35 & $0.00 *$ \\
\hline & & Other/Multi-racial & -0.25 & 0.1 \\
\hline \multirow{7}{*}{$\begin{array}{l}\text { MD check } \\
\text { feet }\end{array}$} & \multirow[t]{4}{*}{$\begin{array}{l}\text { Mexican } \\
\text { American }\end{array}$} & Other Hispanic & -0.02 & 0.86 \\
\hline & & NHW & 0.23 & $0.00 *$ \\
\hline & & NHB & 0.33 & $0.00 *$ \\
\hline & & Other/multi-racial & 0.09 & 0.5 \\
\hline & \multirow[t]{3}{*}{$\begin{array}{l}\text { Other His- } \\
\text { panic }\end{array}$} & NHW & 0.13 & $0.01^{*}$ \\
\hline & & $\mathrm{NHB}$ & 0.18 & $0.00 *$ \\
\hline & & Other/Multi-racial & 0.08 & 0.31 \\
\hline \multirow[t]{5}{*}{$\begin{array}{l}\text { Self-inspec- } \\
\text { tion of feet }\end{array}$} & $\begin{array}{l}\text { Other/Multi- } \\
\text { racial }\end{array}$ & Mexican American & -0.17 & $0.01 *$ \\
\hline & & Other Hispanic & -0.97 & 0.06 \\
\hline & & NHW & -0.93 & $0.04^{*}$ \\
\hline & & NHB & -1.57 & $0.00 *$ \\
\hline & $\mathrm{NHB}$ & NHW & 0.63 & $0.02 *$ \\
\hline
\end{tabular}

to Other Hispanics; and for NHBs when compared to NHWs. HDL was not significantly different for any of the groups, but HDL in NHWs was significantly different than Other Hispanics. Even though for nephropathy, while $74 \%$ of all ethnic groups had normal albumin levels $(<30 \mu \mathrm{g} / \mathrm{mg}) 97 \%$ had elevated creatinine levels $(\geq 1.5 \mathrm{mg} / \mathrm{dl})$. The largest group with microalbumin (30-299 $\mu \mathrm{g} / \mathrm{mg}$ ) was among Mexican Americans (29\%), NHBs (27\%), Other/Multi-racials (26\%), NHWs (17\%), and Other Hispanics (16\%), while for macroalbumin the largest group was with Other Hispanics (10\%), Mexican Americans (8\%), NHBs (6\%), NHWs (4\%), and Other/Multi-racials (2\%). Over $90 \%$ of each ethnic group had elevated creatinine levels (>1.5 mg/dl). Overall, the largest group with combined microalbumin and macroalbumin levels were among Mexican Americans (37\%). For nephropathy, albumin in NHWs was significantly different than Mexican Americans and in NHBs compared to NHWs. For creatinine levels, there was significant difference in Mexican Americans, Other Hispanics, and NHWs when compared separately to NHBs.

For retinopathy, the largest ethnic group with diabetes who reported having last had their pupils dilated 13 months ago or more was among Other Hispanics (28\%), equal for NHWs and Mexican Americans (27\%), NHBs (24\%), and Other/ Multi-racials (19\%). The largest group with diabetes who had never had their pupils dilated were among Mexican Americans (24\%), Other Hispanics (16\%), Other/Multi-racials (9\%), NHWs (5\%), and NHBs (3\%). Overall, $7 \%$ of all ethnic groups with diabetes had never had their pupils dilated and $26 \%$ had them dilated 13 or more months ago. For having had their pupils dilated, there were significant differences in NHWs, NHBs, Other/Multi-racials when compared separately to Mexican Americans; and in NHWs, and NHBs when compared to Other Hispanics.

For ulcers and amputations, $28 \%$ of people in all ethnic groups reported that they had never had a HCPs check their feet within the last year while only $20 \%$ had them checked by a HCP at least once within the past year. The largest ethnic group who never had a HCP check their feet within the past year were among Other Hispanics (42\%), followed by Mexican Americans (40\%), Other/Multi-racials (29\%), NHWs (26\%) and NHBs (21\%). For frequency of sample members self checking their feet, the largest group to check them at least 1 time a day was among NHBs (65\%), Mexican Americans (56\%), NHW (48\%), Other Hispanics (45\%), and Other/Multi-racials (36\%). The largest group who never checked their feet was among Other/Multi-racial (45\%), Other Hispanics (25\%), NHWs (23\%), Mexican Americans (21\%), and NHBs (17\%). Overall, $28 \%$ of all ethnic groups reported never having a HCP check their feet within the past year, and $24 \%$ had not checked their own feet. For frequency of having a HCP check the feet of their patients with diabetes, significant differences were found in NHWs and NHBs when compare separately to Mexican Americans and Other Hispanics. For frequency of those with diabetes self-inspecting their feet, significant differences in 
Judith Aponte. Journal of Diabetes Research and Clinical Metabolism 2012,

Mexican Americans, Other Hispanics, NHWs, and NHBs when compared separately to Other/Multi-racials, and between NHWs and NHBs.

Overall, the group with the highest elevated and high A1c, microalbumin and macroalbumin levels was among Mexican Americans making this group at high-risk for diabetes-related complications, particularly nephropathy. The highest groups with elevated and high SBP and DBP were among NHBs and Other Hispanics, making these groups at high-risk for developing CVD.

No differences in the comparison of ethnic groups for the remaining variables for risk factor of diabetes complication measures, SBP ( $p=.33-.92)$, and cigarette smoking $(p=.07-0.562)$, were found.

\section{Limitations}

There are several limitations to the current study. Firstly, diabetes was defined by self-reporting rather than by the $\mathrm{ADA}^{\prime} \mathrm{s}^{53}$ definition: anyone with an $\mathrm{A} 1 \mathrm{c} \geq 6.5 \%$, a fasting plasma glucose (FPG) of $\geq 126 \mathrm{mg} / \mathrm{dl}$, symptoms of hyperglycemia (e.g., polydipsia, polyuria, and unexplained weight loss) and a casual plasma glucose $\geq 200 \mathrm{mg} / \mathrm{dl}$, or a 2 -hour plasma glucose $\geq 200 \mathrm{mg} / \mathrm{dl}$ during an oral glucose tolerance test (OGTT). Second, cigarette smoking, last dilated pupil exam, frequency practice of a HCP checking the feet of people with diabetes, and frequency of self feet inspections of those with diabetes data were self-reported. Third, NHANES 2009-20120 did not collect data on additional tests and measures (i.e., comprehensive foot exam, aspirin therapy, comprehensive eye exam, and DPN) which did not allow for the diabetes complication neuropathy to be studied or for additional measures for CVD, retinopathy and for ulcers and amputations to be examined.

Despite these limitations, the data provide vital information on risk factors of diabetes-related complications, supporting the need for continuous screening and monitoring of these risk factors and for early identification and early diabetes care interventions.

\section{Discussion of Findings A1c}

The UKPDS [33] and the Action in Diabetes and Vascular Disease: Preterax and Diamicron MR Controlled Evaluation (ADVANCE) [34] study's report, the importance in maintaining glycemic control , blood pressure and the long-term effects this has on the reduction of both microvascular and macrovascular complications. King, Jones, \& Warthen [35] report, elevated glycemic control has also shown to be associated with heart disease, stroke, end-stage renal disease (ESRD), nerve disease, blindness and amputations. These complications can be prevented or managed with optimal control of glycemic levels, blood pressure ranges, triglyceride levels, and smoking cessation.

\section{CVD}

Triplitt and Alvarez [36] reported that approximately $60 \%$ to $80 \%$ of people with diabetes also have hypertension, increasing their risk of myocardial infarction (MI), stroke, nephropathy, and retinopathy. The Hypertension Optimal Treatment (HOT) [37] and Appropriate Blood Pressure Control in Diabetes (ABCD) [38] studies report control of blood pressure significantly reduces CVD events in people with diabetes. Hamet [39] reports that a reduction of SBP of $7.1 \mathrm{mmHg}$, and of DBP of $2.9 \mathrm{mmHg}$ from the normal range $(<130 / 80)$ resulted in a relative risk reduction of $24 \%$ in CVD death. Hence, those in the current study with either an elevated SBP $(\geq 130-139$ $\mathrm{mmHg})$ or elevated DBP $(\geq 80-\leq 89 \mathrm{mmHG})$ and a high SBP $(\geq 140 \mathrm{mmHG})$ or DBP ( $\geq 90 \mathrm{mmHG}$ ) have a $24 \%$ or higher relative risk of CVD death.

As Peters [40] reports, people with diabetes and an elevated LDL cholesterol (> $100 \mathrm{mg} / \mathrm{dl}$ ) have a 7.2 relative risk of death compared to those without diabetes. In addition, the Cholesterol Treatment Trialists' (CTT) Collaboration [41] noted that an LDL reduction in people with diabetes of at least $38 \mathrm{mg} / \mathrm{dl}$, below the normal level of $100 \mathrm{mg} / \mathrm{dl}$, reduces the risk of major vascular events by $20 \%$. Thus, those in the current study with an LDL level above $100 \mathrm{mg} / \mathrm{dl}$ are at a $20 \%$ risk for vascular events. The UKPDS [33] reported as LDL and triglyceride levels increase, and as HDL levels decrease in people with diabetes, the risk of CVD rises. The Fenofibrate Intervention and Event Lowering in Diabetes (FIELD) [42] study reported that people with diabetes with HDL levels $\leq 50 \mathrm{mg} / \mathrm{dl}$ had a $22 \%$ higher risk of CVD, and in those with high triglyceride levels ( $\geq 150 \mathrm{mg} / \mathrm{dl}$ ) there was a $24 \%$ higher risk. Hence, all sample members in the current study with an elevated HDL level had a $22 \%$ higher risk of CVD and $20 \%$ had a $20 \%$ risk of vascular events. As the ADA [43] states, LDL, $\mathrm{HDL}$ and triglyceride level are independent predictors of CVD and preventative measures need to be initiated immediately in order to reduce the morbidity and mortality associated with elevated and high blood pressure ranges and lipid levels.

\section{Nephropathy}

Bruno [44] reports that people with diabetes and microalbuminuria (30-299 $\mu \mathrm{g} / \mathrm{mg}$ ) have a $42 \%$ increased risk of developing macroalbuminuria ( $\geq 300 \mu \mathrm{g} / \mathrm{mg}$ ). The UKPDS [33], reported that people with diabetes and microalbuminuria have a $3 \%$ annual death rate and a $4.6 \%$ rate for those with macroalbuminuria and an $18.9 \%$ rate in people with elevated creatinine levels (Adler, et al, 2003). Early detection and treatment strategies for people with diabetes at risk for developing renal disease are essential, given the association renal disease has with other microvascular complications (e.g., diabetic retinopathy) and macrovascular disease (e.g., CVD).

\section{Retinopathy}

Noble and Chaudhary (2010) report that $40 \%$ to $45 \%$ of people when diagnosed with diabetes have some stage of diabetic 
retinopathy. In the current study, there were $33 \%$ of those who either had their pupils dilated more than 1 year ago or never had, indicating those with potentially undiagnosed retinopathy. This finding shows it is critical for identification of those at risk for diabetic retinopathy and with undiagnosed retinopathy, in order to initiate early treatment.

\section{Ulcers and amputations}

Reiber (1993) states that people with diabetes have a 15\% lifetime risk of developing a foot ulcer. Those with diabetes have a 10 to 30 times risk of having a limb amputation as a result of a foot ulcer than in those without diabetes (Siitonen, Niskanen, Laakso, Siitonen, \& Pyorala, 1993). In people with diabetes, $85 \%$ of non-traumatic amputations are a result of a foot ulcer (Trautner, Haastert, Giani, \& Berger, 1996). Given these statistics and the high risk of foot ulcers in people with diabetes, the ADA (2004f) recommends that health care providers caring for people with diabetes conduct annual examinations of their patients feet and those with diabetes conduct daily examination of their own feet. The findings in this current study show that $28 \%$ have never had an annual foot examine by their HCP, $52 \%$ had it done more than 1year ago, and $20 \%$ had it within the past year. In addition, the findings show that $24 \%$ of people with diabetes do not check their feet daily (i.e., less than 1 time a day), while $24 \%$ never check them. This indicates that approximately $48 \%$ of HCPs are overlooking key opportunities of early identification of high-risk foot conditions (e.g., redden area, open sore) in their patients and disregarding prime times to reinforce the need of daily foot checks.

\section{Conclusion}

Diabetes related complications can be delayed or prevented with continuous glycemic control, smoking cessation, maintaining normal blood pressure ranges, lipid levels (i.e., triglyceride, LDL and HDL levels), and improving practices of HCPs to check the feet of their patient at every diabetes visit, and of those with diabetes checking their own feet on a daily basis. Hence, more education to those with diabetes emphasizing the significance of diabetes follow-up care and of the importance of monitoring and maintaining normal diabetes-related measures (e.g., blood pressure, lipid levels) is critical and crucial in reducing diabetes-related risk factors and improving diabetes care practices given that they impact overall diabetes- health outcomes, quality of life and mortality.

\section{Competing interests}

The authors declare that they have no competing interests.

\section{Publication history}

Editor: Fernando Ovalle, University of

Alabama School of Medicine, USA.

Received: 09-May-2012 Accepted: 06-July-2012

Published: 19-July-2012

\section{References}

1. Centers for Disease Control and Prevention (CDC) 2008 National diabetes fact sheet: general information and national estimates on diabetes in the United States, 2007. Atlanta, Georgia: United States Department of Health and Human Services.

2. American Diabetes Association (ADA) Diabetes Basics. Diabetes Statistics. Accessed March 15, 2012. I Statics info.

3. American Diabetes Association (2011) Diagnosis and classification of diabetes mellitus. Diabetes Care. 2011; 34(Suppl. 1): S62-S69.

4. Deshpande AD, Harris-Hayes M, Schootman M: Epidemiology of diabetes and diabetes-related complications. Phys Ther 2008; 88;(11.);1254-64. | Article | PubMed

5. Fowler MJ. Microvascular and macrovascular complications of diabetes. Clinical Diabetes 2011. 29(3); 116-122. I Article

6. Stratmann B, Tschoepe D: Heart in diabetes: not only a macrovascular disease. Diabetes Care 2011; 34 Suppl 2;(S138-44. | Article | PubMed

7. Reusch JE: Diabetes, microvascular complications, and cardiovascular complications: what is it about glucose? J Clin Invest 2003; 112;(7.);986-8. | Article | PubMed Abstract | PubMed Full $\underline{\text { Text }}$

8. American Diabetes Association (2012) Standards of medical care in diabetes-2012. Diabetes Care 35 (Supp. 1): S11-S63.

9. National Institute of Diabetes and Digestive and Kidney Diseases (NIDDK) (2008) Prevent diabetes problems: Keep your feet and skin healthy. (NIH Publication No. 08-4282). I Article

10. National Institute of Diabetes and Digestive and Kidney Diseases (NIDDK) (2011) The A1c Test and Diabetes. (NIH Publication No. 11-7816). Accessed April 26, 2012. | Article

11. Stratton IM, Adler Al, Neil HA, Matthews DR, Manley SE, Cull $\mathrm{CA}$, et al.: Association of glycaemia with macrovascular and microvascular complications of type 2 diabetes (UKPDS 35): prospective observational study. BMJ 2000; 321;(7258.);40512. | Article | PubMed

12. American Heart Association (2008) Heart Disease and Stroke Statistics-2008 Update. Dallas, Texas.

13. Sibal L, Agarwal SC, Home PD: Carotid intima-media thickness as a surrogate marker of cardiovascular disease in diabetes. Diabetes Metab Syndr Obes 2011; 4;(23-34. I Article I PubMed

14. Liu J, Sempos C, Donahue RP, Dorn J, Trevisan M, Grundy SM: Joint distribution of non-HDL and LDL cholesterol and coronary heart disease risk prediction among individuals with and without diabetes. Diabetes Care 2005; 28;(8.);1916-21. | Article I PubMed

15. American Diabetes Association (2008) Economic costs of diabetes in the U.S. in 2007. Diabetes Care 31(3):1-20.

16. National Institute of Diabetes and Digestive and Kidney Diseases (NIDDK) (2006) Glomerular Diseases. (NIH Publication No. 064358). | Article | PubMed Abstract | PubMed Full Text. Accessed April 12, 2012. | Article

17. National Institute of Diabetes and Digestive and Kidney Diseases (NIDDK) (2010) Prevent kidney problems: Keep your kidneys healthy. (NIH Publication No. 10-4281L). | Article | PubMed Abstract | PubMed Full Text. Accessed April 15, 2012. | Article 18. Lauretani F, Maggio M, Pizzarelli F, Michelassi S, Ruggiero C, 
Judith Aponte. Journal of Diabetes Research and Clinical Metabolism 2012,

Ceda GP, et al.: Omega-3 and renal function in older adults. Curr Pharm Des 2009; 15;(36.);4149-56. | Article I PubMed Abstract I PubMed Full Text

19. United States Renal Data System (USRDS) (2007) Annual Data Report. Bethesda, Maryland: National Institute of Diabetes and Digestive and Kidney Diseases, National Institutes of Health, U.S. Department of Health and Human Services.

20. American Diabetes Association (2004) Nephropathy in diabetes. Diabetes Care 27(Suppl. 1):S79-S83.

21. American Optometric Association (n.d.) Diabetic retinopathy. Accessed April 12, 2012. I Article

22. Centers for Disease Control and Prevention (2003) History of foot ulcer among persons with diabetes---United States, 20002002. Morbidity and Mortality Weekly Report 52(4): 10981102.

23. Guyton GP, Saltzman CL: The diabetic foot: basic mechanisms of disease. Instr Course Lect 2002; 51;(169-81. I PubMed

24. Armstrong DG, Lipsky BA: Diabetic foot infections: stepwise medical and surgical management. Int Wound J 2004; 1;(2.);123-32. I Article I PubMed

25. Armstrong DG, Lavery LA: Diabetic foot ulcers: prevention, diagnosis and classification. Am Fam Physician 1998; 57;(6.);1325-32, 37-8. | Article I PubMed

26. Centers for Disease Control and Prevention. National Diabetes Fact Sheet: national estimates and general information on diabetes and prediabetes in the United States, 2011. Atlanta, Georgia: U.S. Department of Health and Human Services, Centers for Disease Control and Prevention. 2011.

27. Saydah SH, Eberhardt MS, Loria CM, Brancati FL: Age and the burden of death attributable to diabetes in the United States. Am J Epidemiol 2002; 156;(8.);714-9. | Article | PubMed

28. Aponte J: Diabetes risk factors in Mexican Americans with diabetes. Medsurg Nurs 2009; 18;(5.);265-71, 301; quiz 272. | PubMed

29. National Center for Health Statistics (n.d.) NHANES 2009-2010 Public Data General Release File Documentation. Accessed March 1, 2012. I Article

30. National Center for Health Statistics (n.d.) National Health and Nutrition Examination Survey, NHANES 2009-2010, Data, Documentation, Codebooks, SAS Code, Accessed January 10, 20012. I Article

31. National Center for Health Statistics (n.d.) Analytic and Reporting Guidelines, The National Health and Nutrition Examination Survey (NHANES), Accessed March 1, 2012. | Article

32. National Center for Health Statistics (2004) Analytic Guidelines, NHANES Analytic Guidelines June 2004 Version,. Accessed January 10, 2012. I Article

33. UK Prospective Diabetes Study (UKPDS) Group (1998) Intensive blood-glucose control with sulphonylureas or insulin compared with conventional treatment and risk of complications in patients with type 2 diabetes (UKPDS 33) Lancet 352(9131): 837-853.

34. Patel A, MacMahon S, Chalmers J, Neal B, Billot L, Woodward $M$, et al.: Intensive blood glucose control and vascular outcomes in patients with type 2 diabetes. N Engl J Med 2008; 358;(24.);2560-72. I Article I PubMed

35. King KD, Jones JD, Warthen J: Microvascular and Macrovascular
Complications of Diabetes Mellitus. American Journal of Pharmaceutical Education 2005; 69;(5.);87. I Article

36. Triplitt C, Alvarez CA. Best practices for lowering the risk of cardiovascular disease in diabetes. Diabetes Spectrum 2008. 21(3): 177-189. | Article

37. Hansson L, Zanchetti A, Carruthers SG, Dahlof B, Elmfeldt D, Julius $S$, et al.: Effects of intensive blood-pressure lowering and low-dose aspirin in patients with hypertension: principal results of the Hypertension Optimal Treatment (HOT) randomised trial. HOT Study Group. Lancet 1998; 351;(9118.);1755-62. I Article I PubMed

38. Estacio RO, Jeffers BW, Gifford N, Schrier RW: Effect of blood pressure control on diabetic microvascular complications in patients with hypertension and type 2 diabetes. Diabetes Care 2000; 23 Suppl 2;(B54-64. I PubMed

39. Hamet P: What matters in ADVANCE and ADVANCE-ON. Diabetes Obes Metab 2012; 14 Suppl 1;(20-9. I Article I PubMed

40. Peters AL. Clinical relevance of non-HDL cholesterol in patients with diabetes. Clinical Diabetes 2008. 26(1): 3-7. | Article

41. Cholesterol Treatment Trialists' (CTT) Collaboration (2010) Efficacy and safety of more intensive lowering of LDL cholesterol: a meta-analysis of data from 170000 participants in 26 randomised trials. Lancet 376(9753): 1670-1681.

42. Scott R, O'Brien R, Fulcher G, Pardy C, D'Emden M, et al. Effects of fenofibrate treatment on cardiovascular disease risk in 9,795 individuals with type 2 diabetes and various components of the metabolic syndrome. Diabetes Care 2009. 32(3): 493-498. | Article

43. Haffner SM: Dyslipidemia management in adults with diabetes. Diabetes Care 2004; 27 Suppl 1;(S68-71. | Article | PubMed

44. Bruno G, Merletti F, Biggeri A, Bargero G, Ferrero S, Pagano G, et al.: Progression to overt nephropathy in type 2 diabetes: the Casale Monferrato Study. Diabetes Care 2003; 26;(7.);2150-5. | Article | PubMed

45. Adler Al, Stevens RJ, Manley SE, Bilous RW, Cull CA, Holman RR: Development and progression of nephropathy in type 2 diabetes: the United Kingdom Prospective Diabetes Study (UKPDS 64). Kidney Int 2003; 63;(1.);225-32. I Article I PubMed

46. Noble J, Chaudhary V (2010) Diabetic retinopathy. Canadian Medical Association Journal 182(15): 1646.

47. Reiber GE (2001) Epidemiology of Foot Ulcerations and Amputations in Diabetes. (6th ed), St. Louis, Missouri, Mosby. I Book

48. Siitonen OI, Niskanen LK, Laakso M, Siitonen JT, Pyorala K: Lower-extremity amputations in diabetic and nondiabetic patients. A population-based study in eastern Finland. Diabetes Care 1993; 16;(1.);16-20. | PubMed

49. Trautner C, Haastert B, Giani G, Berger M: Incidence of lower limb amputations and diabetes. Diabetes Care 1996; 19;(9.);1006-9. | Article I PubMed

50. American Diabetes Association (2004) Preventative foot care in diabetes. Diabetes Care 27(Suppl. 1): S63-S64. 